\title{
ACIDENTES CAUSADOS POR SERPENTES DO GÊNERO Crotalus EM PEQUENOS ANIMAIS - REVISÃO DE LITERATURA
}

RODRIGUES, Flávia Raquel ${ }^{1}$

ANTONUSSI, Thaís Daniele ${ }^{1}$

SILVA, Giovane Munhoz Alves da ${ }^{1}$

NARDO, Carla Daniela Dan de ${ }^{2}$

SALVADOR, Rosana da Cruz Lino ${ }^{2}$

GALVÃO, André Luiz Baptista ${ }^{3}$

\begin{abstract}
RESUMO: O Brasil possui cerca de 265 espécies de serpentes, classificadas dentro de 70 gêneros, reunidos em 9 famílias. O gênero Crotalus está representado no Brasil principalmente pela Crotalus durissus, que possui também uma ampla distribuição geográfica. O veneno crotálico quase não produz lesão no local da picada, mas as marcas das presas podem ser encontradas. Não há dor ou se existe é de pequena intensidade, entretanto devido sua ação neurotóxica, este veneno pode induzir ao óbito logo após a picada, tanto no homem quanto em animais. Considerando a importância dos acidentes ofídicos na medicina veterinária, principalmente na clínica de pequenos animais, e que os dados sobre acidentes ofídicos são escassos, objetiva-se com este trabalho a descrição dos principais aspectos clínicos e patológicos ocorridos em pequenos animais em decorrência a acidente crotálico.
\end{abstract}

Palavras-chave: Acidente ofídico. Serpentes. Veneno.

\section{ACCIDENT CAUSED BY Crotalus IN SMALL ANIMALS - REVIEW}

SUMMARY: The in Brazil has about 265 snake species, classified into 70 genera, meeting in 9 families. The Crotalus genus is represented in Brazil mainly by Crotalus durissus, which also has a wide geographical distribution. The venom produces almost no local lesion, but the fangs of brands can be found. There is no pain or if there is low intensity, however due to its neurotoxic action, this poison can lead to death soon after the bite, both in man and animals. Considering the importance of snake bites in veterinary medicine, particularly in the clinic for small animals, and that data on snake bites are rare, objective yourself with this job description of the clinical and pathological features occurring in small animals due to accident crotalic.

Keywords: Ophidic acciden. Snakes. Poison.

\section{INTRODUÇÃO}

Os acidentes ofídicos são motivo de grande preocupação em nosso país, principalmente pelo fato de possuirmos as características ambientais apropriadas para o habitat e

\footnotetext{
${ }^{1}$ Graduanda em Medicina Veterinária - Centro Universitário de Rio Preto (UNIRP)

${ }^{2}$ Docente Centro Universitário de Rio Preto (UNIRP)

${ }^{3}$ Docente UNIRP - Centro Universitário de Rio Preto-FCAV - UNESP Jaboticabal-SP- Graduado em Medicina Veterinária pela Universidade para o Desenvolvimento do Estado e da Região do Pantanal - Campo Grande (MS) (2004). Especialista em Clínica Médica de Pequenos Animais pelo programa de Aprimoramento realizado no Hospital Veterinário "Governador Laudo Natel" - FCAV/Unesp - Jaboticabal (SP) (2008). Mestre em Clínica Médica de Pequenos Animais com ênfase em Nefrologia e Urologia - pela mesma IES (2010). Atualmente na mesma IES é Doutorando em Clínica Médica de Pequenos Animais com ênfase em Nefrologia e Urologia. Apresenta interesse e desenvolve trabalhos de pesquisa na área de Clínica Médica de Pequenos Animais.
} 
desenvolvimento das serpentes peçonhentas (PEREIRA et al., 2006).

Todos os animais domésticos estão susceptíveis a serem vítimas de acidentes ofídicos, porém existem variações. Os grandes animais são mais susceptíveis, devido seu hábito alimentar e ambiente em que vivem, porém, eles necessitam de um volume de veneno maior a ser inoculado para ocasionar o óbito, quando comparados aos pequenos animais. Nos animais de companhia, são descrições raras os relatos de acidentes ofídicos em gatos, porém é comum em cães, devido ao fato da espécie apresentar um comportamento curioso frente a algo desconhecido. Chiacchio et al., (2011) descreveram que a região anatômica mais atingida pela picada de cobra em cães é a cabeça seguida pelos membros.

A nomenclatura utilizada nesta revisão de literatura compreende na utilização da taxonomia clássica, visto que existe uma nova proposta pela comunidade científica quanto a taxonomia, entretanto a mesma ainda está em estudo (PYRON, BURBRINK, WIENS, 2013).

As serpentes do Gênero Crotalus são conhecidas popularmente como cascavéis, boicininga, boiquira ou maracambóia, pertencem à família Viperidae e subfamília Crotalinae. Possuem muitas espécies e subespécies distribuídas desde o Sul do Canadá até o norte da Argentina (PINHO; PEREIRA, 2001; ANDRADE FILHO et al., 2001).

No Brasil, a única espécie encontrada é a Crotalus durissus, representada por sete subespécies: Crotalus d. cascavella, Crotalus d. collilineatus, Crotalus d. dryinas, Crotalus d. marajoensis, Crotalus d. ruruima, Crotalus d. terrificus e Crotalus d. trigonicus (CAMPBELL; LAMAR, 1989), porém, Wüster et al., (2005) consideram desnecessária a distinção em subespécies e propõe que Crotalus durissus cascavella e C. durissus collilineatus sejam considerados sinônimos de $C$. d. terrificus.

São serpentes robustas, pouco ágeis, de porte médio, não são agressivas e quando se sentem ameaçadas denunciam a sua presença pelo ruído característico do guizo presente na extremidade de sua cauda, a cada nova ecdise que a serpente realiza durante a sua vida, da origem a um anel do guizo, desmitificando a lenda de que cada anel do guizo corresponde a um ano da serpente, visto que elas podem realizar várias ecdises durante o ano (BELLUOMINI, 1984).

Esta serpente é responsável por cerca de 8 a $15 \%$ dos acidentes ofídicos notificados anualmente em humanos no Brasil, e é a principal causadora de óbitos entre os acidentes ofídicos devido à gravidade do quadro sistêmico. Com relação às estatísticas dos acidentes ofídicos na medicina veterinária, os relatos são escassos e não condizem com a realidade, visto que não existe obrigatoriedade de notificação assim como existe na medicina humana.

Considerando a importância dos acidentes ofídicos na medicina veterinária, principalmente na clínica de pequenos animais, e que os dados sobre acidentes ofídicos são escassos, objetiva-se com este trabalho a descrição das propriedades do veneno, principais 
aspectos clínicos e medidas terapêuticas em decorrência a acidente crotálico em pequenos animais.

\section{PROPRIEDADES DO VENENO CROTÁLICO DE SINAIS CLÍNICOS}

O veneno crotálico possui atividade neurotóxica (por inibição da acetilcolina na placa motora), coagulante (relacionada ao consumo de fibrinogênio e incoagulabilidade sanguínea), miotóxica sistêmica, nefrotóxica, hepatotóxica e hemolítica, geralmente não produz lesão local da picada, sendo difícil identificar até mesmo as marcas das presas, porém um edema e equimoses de pequena intensidade podem estar presentes (BARRAVIERIA et al., 1999; MARTINS et al., 1998).

As manifestações clínicas decorrentes da atividade neurotóxica começam a aparecer algumas horas após o acidente e são caracterizadas por fáceis miastênica (parestesia dos músculos faciais), apresentando ptose palpebral uni ou bilateral, flacidez da musculatura da face, midríase bilateral, oftalmoplegia, visão turva e/ou diplopia, indicando, o comprometimento do III, IV e VI pares de nervos cranianos (CARDOSO et al., 2003). Nogueira et al., (2007) descreveram em cães, o aparecimento de ataxia, sedação leve a moderada, incapacidade em movimentar os membros, incapacidade de levantar a cabeça, adicionalmente, descreveram que o veneno atinge tanto o sistema nervoso central quanto o sistema nervoso periférico.

A miotoxidade é caracterizada por uma intensa dor muscular generalizada, acompanhada ou não de edema muscular. A lesão das fibras musculares esqueléticas (miólise) leva a liberação de mioglobina e consequentemente uma mioglobinúria que pode ocasionar o escurecimento da urina. As alterações laboratoriais são marcadas por aumento de enzimas marcadoras de lesão muscular como creatinoquinase (CK), lactato desidrogenase (LDH) e alanina de aminotransferase (ALT) (PINHO; PEREIRA, 2001).

Algumas horas após a picada o efeito coagulante do veneno pode ser evidenciado por aumento do tempo de coagulação ou incoagulabilidade sanguínea ocasionada pelo consumo de fibrinogênio. $\mathrm{O}$ veneno possui uma fração tipo trombina que converte o fibrinogênio diretamente em fibrina, consequentemente uma afibrinogenemia ocorre, entretanto, geralmente não ocorrem alterações quanto ao número de plaquetas, mas estas podem sofrer agregação (AMARAL et al., 1988; BARRAVIERA, 1990).

Bancher et al., (1973) descreveram que o veneno crotálico se fixa preferencialmente em tecidos hepáticos e nervosos. Barraviera (1999) relatou o aumento das dosagens séricas de aspartato transaminase (AST) e alanina aminotransferase (ALT) em pacientes sob ação do veneno crotálico, também demonstrou em diversos estudos a ocorrência de extensas áreas de necrose em 
fígado de pacientes humanos que vieram a óbito após acidente crotálico. Também relatou que em seres humanos a hepatotoxidade do veneno crotálico se deve a dois mecanismos: lesão de mitocôndrias e efeito de citocinas nos hepatócitos.

O veneno é excretado predominantemente pelos rins. Alguns componentes do veneno crotálico atuam direta e indiretamente sobre as células renais, possuindo maior seletividade pelos túbulos proximais, que pode ser comprovada pela elevação da fração de sódio e potássio excretados. (MALAGUTTI; FERRAZ 2011).

Adicionalmente, o veneno crotálico é uma mistura complexa, composto por várias substâncias, sendo as principais cinco toxinas (crotoxina, crotamina, giroxina, convulxina e delta toxina), enzimas (5-nucleotidase, fosfodiesterase, trombina-like, L-aminooxidase, e DNA hidrolase) e peptídeos. (RANGEL-SANTOS et al., 2004, VITAL BRAZIL, 1980).

A crotoxina é o principal componente de caráter tóxico do veneno crotálico, sendo responsável por cerca de $80 \%$ da letalidade e $60 \%$ do peso seco do veneno, de peso molecular de 23 a $26 \mathrm{kDa}$. É formada pela associação não covalente de duas subunidades, sendo elas, a crotapotina (subunidade $\mathrm{CA}$ ), de caráter ácido que não apresenta atividade enzimática nem tóxica, com peso molecular de 8 a $9 \mathrm{kDa}$, e a fosfolipase A2 (FLA2 - subunidade CB), de caráter básico exercendo atividade miotóxica, citotóxica, inflamatória e neurotóxica, com peso molecular de $14 \mathrm{kDa}$, a função dessa subunidade não está totalmente caracterizada, porém, acredita-se que esta molécula atue como carreadora da subunidade FLA2, potencializando a atividade letal desta subunidade. (BRASIL, 1994; SOARES, MANCIN et al., 2001). É uma neurotoxina pré-sináptica que atua nas terminações nervosas impedindo a liberação de acetilcolina pelos impulsos nervosos. Essa inibição é responsável pelo bloqueio neuromuscular e, portanto, pelas paralisias motoras e respiratórias observadas nos animais, podendo levar a óbito por asfixia. A paralisia é flácida e acomete os músculos respiratórios, esqueléticos, da face e do globo ocular (Bon et al. 1979).

A crotamina corresponde a cerca de $17 \%$ do peso seco do veneno e possui o peso molecular de cerca de 4,8 kDa exercendo atividade exclusivamente miotóxica, segundo Chang; Tseng (1978), ela atua ativando os canais de sódio e cálcio, aumentando o seu influxo, causando despolarização da membrana e forte contração muscular.

A convulxina, possui um peso molecular de cerca de $70 \mathrm{kDa}$, induz a síntese de tromboxano A2 causando agregação plaquetária, também é responsável por convulsões, distúrbios circulatórios e respiratórios. (BARRAVIERA, 1990; VITAL BRAZIL ET al. 2006).

A giroxina, não é considerada letal e foi descrita por Barrio (1961), como uma substância que produz sintomas relacionados ao equilíbrio como quedas seguidas de rolamento. 
A delta toxina foi estudada por Vital Brazil (1980), sendo isolada da subespécie Crotalus durissus terrificus, possui $40 \mathrm{kDa}$ de peso molecular e é uma proteína ativadora do fator X que ativa a agregação plaquetária, o EDTA, a benzamidina e D-galactose não inibiram a atividade da toxina.

Devido a ação hemolítica do veneno, inicialmente o hemograma costuma apresentar uma discreta leucocitose com neutrofilia, diminuição do número de hemácias, concentração de hemoglobina e da percentagem do hematócrito (NOGUEIRA, 2007; AZEVEDO-MARQUES et al., 1990; BARRAVIERA, 1990).

Como complicação da ação direta e indireta do veneno nas células renais pode ocorrer a insuficiência renal aguda (IRA), sendo esta, a alteração sistêmica mais importante e a principal causa de óbito após acidente crotálico (MALAGUTTI; FERRAZ 2011). Segundo Monteiro et al., (2001) e Martins et al., (2002) o componente responsável pela nefrotoxidade direta é a crotoxina. O diagnóstico de IRA pode ser realizado através da elevação progressiva das concentrações séricas de ureia, creatinina e diminuição do débito urinário, com manifestações clínicas como oligúria e anúria. Segundo Brasil, (1998), a alteração histológica mais comum nos casos de IRA em decorrência ao acidente crotálico é caracterizada por lesão renal aguda por obstrução tubular por cilindros de mioglobina em decorrência de mioglobinúria secundária a miólise.

\section{DIAGNÓSTICO E TRATAMENTO DO ACIDENTE CROTÁLICO}

O diagnóstico clínico do acidente crotálico baseia- se principalmente na observação de manifestações neurológicas, e ausência de sinais inflamatórios no local da picada e sangramentos (BRASIL, 1934). A técnica de ELISA pode ser utilizada para confirmação laboratorial do envenenamento crotálico (BARRAVIEIRA 1990; BRASIL, 1998; FILHO 1997). Pode-se verificar a presença de mioglobina tanto no soro quanto na urina, elevação nos valores séricos de creatinoquinase (CK), lactato desidrogenase (LDH), e de AST, confirmando a miólise, decorrente da miotoxidade ocasionada principalmente pela ação da crotamina (CARDOSO et al., 2003).

A utilização da soroterapia antiveneno deve ser realizada adequada e precocemente, com o intuito de neutralizar a maior quantidade de toxinas possíveis diminuindo a gravidade do quadro. Deve-se evitar fazer uso de fármacos nefrotóxicos, deve-se prevenir a mioglobinúria estabelecendo um alto fluxo urinário para diminuir a concentração intratubular de mioglobina, diminuir o tempo de exposição das células tubulares ao pigmento e minimizar os riscos de precipitação e consequente obstrução tubular por mioglobina através de fluidoterapia para expansão volêmica adequada (BRASIL, 1998; BARRAVIERA et al., 1990). Manter manejo 
alimentar com dietas com baixo teor de proteínas e potássio (BARRAVIEIRA et al., 1990; JORGE et al., 1992).

O único tratamento comprovadamente eficaz para neutralizar os componentes do veneno crotálico é a soroterapia heteróloga ou soroterapia específica, no entanto, deve-se associar a terapia de suporte visando diminuir os riscos de complicações. Existem dois tipos de soroterapia para vítimas de acidentes crotálicos: soro antiofídico botrópico-crotálico (heterólogo) e soro antiofídico especificamente crotálico, o objetivo é neutralizar a maior parte de veneno circulante, uma ampola de soro $(10 \mathrm{ml})$ neutraliza $15 \mathrm{mg}$ de veneno, em casos de acidente crotálico o recomendado é que se neutralize no mínimo 50 mg de veneno (BRASIL, 1998).

\section{PROPRIEDADES FARMACOLÓGICAS DO VENENO CROTÁLICO}

Embora, o veneno crotálico tenha um grande potencial tóxico, sendo muitas vezes letal, vários estudos demonstraram que além de neurotóxico, nefrotóxico, hemolítico, coagulante, hepatotoxico, citotóxico e miotóxico, em doses não tóxicas possui efeito antiinflamatório, (LANDUCCI et. al., 1995; NUNES, 2007), analgésico (MANCIN et al.,1998; KONNO et al., 2008; BRIGATTE et al., 2001; BRIGATTE et al., 2004), antiviral (MULLER et. al., 2012) e antitumoral (HERNANDEZ PLATA et al., 1993; SOARES et al., 2010; LIPPZ, 1994).

Landucci et al., (1995) descreveram em seu estudo que o componente responsável pela ação antiinflamatória do veneno, é a crotapotina. Neste estudo, observou-se a redução do edema de pata de camundongos induzido por carragenina, uma substância obtida a partir de extratos de um musgo marinho da Irlanda denominado Chondrus crispus que desencadeia uma intensa resposta inflamatória caracterizada pelos altos níveis de prostaglandinas (PGs) e leucotrienos presentes no exsudato. Em seu estudo, Nunes (2007), conferiu a propriedade antiinflamatória da crotapotina pela diminuição da migração de células polimorfonucleares no local do edema.

Mancin et al., (1998) demonstraram o efeito antinociceptivo da crotamina em ratos por meio de placa quente e contorção por ácido acético, e relataram ainda que quando comparada a morfina em doses extremamente baixas $(133,4 \mu / \mathrm{kg})$ é aproximadamente 30 vezes mais potente. Além da crotamina, Konno et al., (2008) demonstraram a ação analgésica de um peptídeo isolado do veneno crotálico denominado de crotalfina. Este peptídeo promove analgesia por atuar nos receptores opióides kappa e delta. Apesar de atuar em receptores opiáceos, a crotalfina não causa o desenvolvimento de dependência e/ou sinais de abstinência. O terceiro componente com propriedades analgésicas, isolado do veneno crotálico é a crotoxina, efeito esse observado em ratos que foram submetidos a modelos de dor inflamatória, neuropática ou oncológica (BRIGATTE et al., 2001; BRIGATTE et al., 2004). 
Muller et al., (2012), atribuiram a ação antiviral a fração CB da crotoxina (Fosfolipase A2) contra o vírus da febre amarela de dengue. Neste estudo, a replicação viral foi inibida em sua fase inicial e atribui a esta inibição principalmente pela ação catalítica da FA2.

A ação antitumoral foi demonstrada por Hernandez-Plata et. al., (1993), através do tratamento de células de sarcoma em ratos, com as frações de crotoxina e crotamina. Os resultados deste estudo tanto em relação à regressão do tumor, quanto à sobrevida dos animais foram muito satisfatórios. Soares et al., (2010) também estudaram o efeito antitumoral do veneno e ressaltam que este efeito é provavelmente mediado pela indução da apoptose, porém seu mecanismo de ação não está totalmente esclarecido. Neste estudo, o veneno da Crotalus durissus terrificus apresentou poder citotóxico significativamente maior que a cisplatina, um fármaco usado clinicamente para tratamento de tumores. Montecucco et al., (2008) e Sampaio et al., (2010) referiram que o mecanismo pelo qual a PLA2 induz a lesão celular é uma característica inovadora, as lesões são consequência de uma perturbação da membrana plasmática que promove um grande influxo de $\mathrm{Ca} 2+$ levando à degradação celular, concluindo, portanto que a sua ação é dependente do cálcio extracelular.

\section{CONCLUSÃO}

O veneno das serpentes do gênero Crotalus é considerado letal por conta da gravidade do quadro sistêmico, podendo levar a óbito por IRA ou por comprometimento neurológico. O diagnóstico clínico é feito com base na observação de sinais neurológicos, ausência de sinais inflamatórios no local da picada e ausência de sangramentos. Para minimizar os danos é necessário a administração adequada e precoce do soro antiofídico que visa neutralizar a maior quantidade de toxinas do veneno. Quanto as propriedades farmacológicas dos componentes do veneno, vários estudos foram realizados demonstrando resultados animadores para o desenvolvimento de novas terapias, contudo, são necessários estudos mais detalhados das atividades de cada composto para uma melhor compreensão dos fenômenos fisiológicos e da aplicação de tais substâncias na terapêutica.

\section{REFERÊNCIAS}

AMARAL, C.F.S.; RESENDE, N.A.; PEDROSA, T.M.G. Afibrinogenemia secundária a acidente ofídico crotálico. Revista do Instituto de Medicina Tropical de São Paulo, São Paulo. 30:288, 1988. 
ANDRADE FILHO, A.; CAMPOLINA, D.; DIAS, M.B. Toxicologia na prática clínica. Ed.Folium, Belo Horizonte, MG, p72-107,2001.

BANCHER, W.; ROSA, R.R.; FURLANETTO, R.S. Estudos sobre a fixação eletiva e quantitativa do veneno de Crotalus durissus terrificus nos tecidos nervoso, renal, hepático e muscular de Mus musculus. Memórias do Instituto Oswaldo Cruz, Linneus, 1758.

BARRAVIERA, B. 1999. Acidentes por serpentes dos gêneros Crotalus e Micrurus. Pp. 281 295 In: Barraviera, B. (Coord.). Venenos - Aspectos clínicos e terapêuticos dos acidentes por animais peçonhentos. EPUB, Rio de Janeiro, 1999.

BARRIO, A. Gyroxin, a new neurotoxin of Crotalus durissus terrificus venom. Acta physiologica latinoamericana, v.11, p.224, 1961.

BELLUOMINI, H. E. Conhecimentos sobre as serpentes brasileiras e medidas de prevenção de acidentes. Revista Brasileira de Saúde Ocupacional, v. 12, p. 82-96, 1984.

BON, C., BOUCHIER, C. et al. Crotoxin, half-century of investigations on a phospholipase A2 neurotoxin. Acta physiologica latinoamericana, v. 39, n. 4, p. 439-448, 1979.

BRASIL. MINISTÉRIO DA SAÚDE. Manual de diagnóstico e tratamento de acidentes por animais peçonhentos. 1a reimpressão. Brasília: Fundação Nacional de Saúde, 1994.

BRASIL, MINISTÉRIO DA SAÚDE. Manual de diagnóstico e tratamento de acidentes por animais peçonhentos. Brasília: Fundação Nacional de Saúde, 1998.

BRASIL, MINISTÉRIO DA SAÚDE. Manual de diagnóstico e tratamento de acidentes por animais peçonhentos. Brasília: Fundação Nacional de Saúde, 1934.

BRIGATTE, P. et al. Tolerance to the antinociceptive effect of Crotalus durissus terrificus snake venom in mice is mediate by pharmacodynamic mechanisms. Toxicon, v.39, p.1399-1410, 2001.

BRIGATTE, P. et al. Whole Crotalus durissus terrificus snake venom induces antinociception in a rat model of cancer pain and crotoxin inhibits tumor growth. In: INTERNATIONAL SYMPOSIUM OF NITRIC OXIDE, CYTOKINES AND INFLAMMATION, 2004, Rio de Janeiro, RJ. Proceedings.Rio de Janeiro: International Symposium of Nitric Oxide, Cytokines and Inflammation, p.127, 2004.

CAMPBELL, J.A.; LAMAR, W.W. Venomous reptiles of Latin America. New York: Cornell University Press, 425p. 1989.

CARDOSO, J.L.C.et al., Animais Peçonhentos no Brasil: biologia, clínica e terapêutica dos acidentes. Ed Savier, São Paulo, SP, 468 p. 2003.

CHIACCHIO, S.B. et al., Triple bothropic envenomation in horses caused by single snake. Journal Venom Animals Toxins, v. 17, n.1, p. 111-117, 2011.

CHIANG, N., SERHAN, C. N. et al. The lipoxin receptor ALX: potent ligand-specific and stereoselective actions in vivo. BMC Pharmacology and Toxicology, v. 58, n. 3, p. 463-487, 1978 . 
FILHO A.A. Acidentes provocados por animais peçonhentos. In: Ratton ILA. (ed). Medicina Intensiva, $2^{\text {a }}$ ed. São Paulo, Ed. Atheneu, 1997; 574-79.

HERNANDEZ PLATA G. et al., Contribucion al estudio sobre los efectos antineoplasicos del complejo crotoxina A-B y cobramina (CFA) en sarcomas de rata. CONGRESSO LATINO AMERICANO DE HERPETOLOGIA, 3, São Paulo, 1993. Anais... Campinas: Universidade Estadual de Campinas, 1993.

JORGE, M.T. ; RIBEIRO, L.A. Epidemiologia e quadro clínico por cascavel-sulamericana (Crotalus durissus). Revista do Instituto de Medicina Tropical de São Paulo. São Paulo. 1992.

KONNO, K. et al., Crotalphine, a novel potent analgesic peptide from the venom of the South American rattlesnake Crotalus durissus terrificus. Peptides, 2008, v.29, p.1293-1304.

LANDUCCI, E.C. et al.,. Inhibition of carrageenin-induced rat paw oedema by crotapotin, a polypeptide complexed with phospholipase A2. British Journal of Pharmacology, v.114, p.578583, 1995.

LIPPS, B. V. Selective cytolitic activity of snake venom proteins, atroporin and kaotree on various types of cancer cells. World congress on animal, plant and microbial toxins.

International Society on Toxinology, 1994.

MALAGUTTI; W. et al., Nefrologia: Uma abordagem multidisciplinar. Rio de Janeiro: Rusior 2011

MARTINS, A.M.C.et al. Effects of Crotalus durissus cascavella venom in the isolated rat kidney. Toxicon, v.36, n. 10, p. 1441-1450. 1998.

MONTEIRO, H.S.A et al., Actions of Crotalus durissus terrificus venom and crotoxin on the solated rat kidney. Brazilian Journal Of Medical and Biological Research, v.34, p.1347-52, 2001.

MONTECUCCO C. et al., Cellular pathology induced by snake venom phospholipase A2 myotoxins and neurotoxins: commom aspects of their mechanisms of action. Cellular and molecular life science,v. 65, p. 2897-912, 2008.

MULLER, V. D. M. et al., Crotoxin and phospholipases A2 from Crotalus durissus terrificus showed antiviral activity against dengue and yellow fever viruses. Toxicon, v.59, p.507-515, 2012.

NOGUEIRA, R.M.B. et al., Experimental envenomation with Crotalus durissus terrificus venom in dogs treated with antiophidic serum-part I: clinical evaluation, hematology and myelogram.

Journal of Venomous Animals and Toxins including Tropical, Botucatu, SP, v.13, n.4, 2007.

PEREIRA, M. T. Acidente botrópico em cães. 2006.Especialização em Clínica Médica e Cirúrgica em Pequenos Animais - Universidade Castelo Branco - Campo Grande, MS, 2006. 46 p.

PINHO, F.M.O. et al., Ofidismo: artigo de revisão. Revista 11 da Associação Médica Brasileira, São Paulo, SP, v.47, n.1, p24-29, 2001. 
PYRON, R. A.; BURBRINK, F.; WIENS, J. A phylogeny and revised classification of Squamata, including 4161 species of lizards and snakes. BMC evolutionary biology, v. 13, n. 93, p. 15-53, 2013.

RANGEL-SANTOS A. et al., Immunosuppresive role of principal toxin (crotoxin) of Crotalus durissus terrificus venom. Toxicon, v. 44, n. 6, p. 609-616, 2004.

SOARES M. A. et al., Crotalus durissus terrificus. Venom as a source of antitumoral agents. The journal of venomous animals and toxins including tropical diseases. 16:480-92, 2010.

SOUZA, C. T. et al., Inhibition of mutalysin II, a metalloproteinase from bushmaster snake venom by human alpha2-macroglobulin and rabbit immunoglobulin. Comparative

Biochemistry and Physiology, v. 130(2), p. 155-68, 2001.

VITAL B.O. et al., Pharmacology of crystalline crotoxin. III Cardio-vascular and respiratory effects of crotoxin and Crotalus durissus terrificus venom. Memórias Instituto Butantan, v.33, n.3, p.993-1000, 1980.

WÜSTER, W. et al.,Tracing an invasion: landbridges, refugia and the phylogeography of the Neotropical rattlesnake (Serpentes: Viperidae: Crotalus durissus). Molecular Ecology, Oxford 14:1095-1108, 2005. 